\title{
LA TRANSFERENCIA DE UN MODELO DE INMIGRACIÓN EN LA MONARQUÍA HISPANA: TOMÁS MURPHY EN LA NUEVA ESPAÑA
}

\author{
Gabriela Sofía GonzÁlez Mireles* \\ CONACYT/Ciesas**
}

\begin{abstract}
RESUMEN
En el siglo XVIII, las regiones americanas que conformaron la Monarquía hispana se incorporaron a la acelerada dinámica derivada de los reacomodos geopolíticos de la época, que conllevó su interacción con actores internacionales, principalmente, a través de la actividad mercantil. Los comerciantes fueron quienes mayor éxito tuvieron al actuar como interlocutores de nuevas redes de intereses, negocios y diplomacia. En México, destaca el caso de Tomás Murphy, comerciante malagueño de origen irlandés que actuó como intermediario entre la corona española e Inglaterra, cuyo protagonismo, en parte, se explica por las soluciones que aportó a través de sus vínculos internacionales y los valores culturales inherentes a la comunidad irlandesa, que trasladó exitosamente al virreinato novohispano.
\end{abstract}

PALABRAS CLAVE: Tomás Murphy, comercio, México, Málaga, siglo XVIII

Enviado: 21/01/2020

Aceptado: 13/07/2020

*mirelesgs@ciesas.edu.mx, mirelesgs@hotmail.com

**Consejo Nacional de Ciencia y Tecnología/Centro de Investigaciones y Estudios Superiores en Antropología Social, México. 


\title{
THE TRANSFER OF AN IMMIGRATION MODEL IN THE HISPANIC MONARCHY: TOMÁS MURPHY IN NEW SPAIN
}

\author{
Gabriela Sofía González Mireles* \\ CONACYT/CIESAS ${ }^{* *}$
}

\begin{abstract}
In the 18th century, the nations that were part of the Hispanic Monarchy joined the accelerated dynamics derived from the geopolitical rearrangements of the time which entailed their interactions with international actors, mainly, through commercial activity. The merchants were the most successful when taking the role of interlocutors of the new networks of interests, business and diplomatic activity. In Mexico, the case of Tomás Murphy stands out, an Irish merchant from Malaga who acted as an intermediary between the Spanish Crown and England. In part, his prominence is explained by the solutions he provided through his international links and the series of inherent values of the Irish community that successfully transferred to the viceroyalty of New Spain.
\end{abstract}

KEYWORDS: Tomás Murphy, commerce, México, Málaga, 18th century

Enviado: $21 / 01 / 2020$

Aceptado: $13 / 07 / 2020$

*mirelesgs@ciesas.edu.mx, mirelesgs@hotmail.com

**Consejo Nacional de Ciencia y Tecnología/Centro de Investigaciones y Estudios Superiores en Antropología Social, México. 


\section{INTRODUCCIÓN}

Uno de los episodios más traumáticos de México en su historia es la Guerra de Intervención estadounidense (1846-1848), por la funesta consecuencia de perder más de la mitad de su territorio en ella. En ese acontecimiento destacó la participación del Batallón de San Patricio, un grupo de desertores del ejército estadounidense, conformado principalmente por reclutas irlandeses que se unieron a las fuerzas mexicanas y que se convirtió en el vínculo histórico de referencia con Irlanda. Más allá de este hecho, el conocimiento de la historia de las relaciones entre México e Irlanda se limita a la presencia de algunos irlandeses en este país durante los siglos XIX y XX.

La desvinculación que existe entre el pasado colonial y la historia de México como nación han contribuido a ese desconocimiento pues, a pesar de compartir el espacio de la Monarquía hispana como pasado común, poco se relaciona a ambas naciones. No obstante, existen algunas referencias aisladas que registran la presencia de irlandeses en el virreinato de la Nueva España, como el caso de Guillén de Lampart que en 1650 fue acusado por la Inquisición de herejía y sedición al propugnar la liberación de los indígenas esclavizados. Para el siglo XVIII, aumentan los casos estudiados y corresponden a funcionarios y militares que actuaron durante el último periodo de vida colonial, el más importante de ellos fue Juan O'Donojú, primer jefe político superior y capitán general de Nueva España.

Diversos estudios han reconstruido los vínculos históricos de Irlanda con la Monarquía hispana, extendiendo la investigación a sus colonias americanas, lo que da pautas para reconocer a estos actores y escribir una historia propia sobre su integración y contribución en esas diferentes regiones.

El presente trabajo, pretende hacer visible a uno de esos actores, Tomás Murphy, un comerciante nacido en Málaga, de padre irlandés y madre andaluza, que se estableció en el virreinato de Nueva España en la última década del siglo XVIII, un momento particular en la Monarquía hispana por el contexto bélico de los imperios europeos, la reorganización de los circuitos del comercio internacional y las medidas reformistas del gobierno de los Borbones.

Este comerciante malagueño, a diferencia de la "casta" de comerciantes que controló el tradicional sistema de comercio en México, perteneció a un nuevo perfil de inmigrante peninsular que, las dos últimas décadas del siglo, ocupó los espacios económicos generados por el desmantelamien- 
to del monopolio mercantil ${ }^{1}$. La relevancia de su trayectoria, además de proceder del aprovechamiento ventajoso del reacomodo de intereses por la implementación del comercio libre, provino de la transferencia y adaptación de los recursos procedentes de su origen irlandés, que le facilitaron las interacciones con el mundo anglosajón, hecho que lo colocó como un actor de primer orden en el complejo momento de transición del virreinato novohispano a la nación mexicana.

A través de una revisión histórica de la trayectoria de Tomás Murphy, basada en fuentes de archivo y bibliografía, se reconstruyen los principales momentos de su vida y se analizan aquellos en los que se trasladaron algunos de los elementos que caracterizaron a la comunidad irlandesa en su diáspora a la Monarquía hispana, específicamente del grupo que se estableció en Andalucía, que por las circunstancias político-económicas que se busca aclarar, jugaron un papel particular.

El artículo lo divido en dos partes, en la primera, busco caracterizar las particularidades de la migración irlandesa a la Monarquía hispana bajo el régimen Borbón, de manera específica en Málaga, haciendo énfasis en las relacionadas al ámbito comercial, materia en que se desenvolvió el protagonista de este trabajo. En la segunda, expongo brevemente la trayectoria de Tomás Murphy, donde destaco los acontecimientos en los que se aprecian elementos característicos del sistema de valores irlandeses, los cuales, este comerciante trasladó a la Nueva España y repercutieron en el momento crítico en el que se gestaba la separación de su metrópoli.

\section{MÁlAGA: ORIGEN DE LA FAMILIA MURPHY PORRO}

La migración irlandesa durante la época moderna en Europa fue un fenómeno relacionado al conflicto político-religioso por la separación de Inglaterra de la iglesia católica en el siglo XVI, la cual se radicalizó con la revolución inglesa de 1689 y el exilio de Jacobo II Estuardo, que tras de sí llevó una ola migratoria de seguidores católicos, entre los que se contaban muchos nobles irlandeses. Estos se integraron en la milicia, el clero y el comercio, actividades en las que, por su filiación católica, tuvieron una buena acogida y obtuvieron privilegios sobre otros extranjeros. Ya en el siglo XVIII, apoyaron la causa de la dinastía Borbón en la Guerra de Sucesión, lo que les otorgó concesiones más amplias y un papel protagónico en su corte, participando activamente en el proyecto de reformas

1. D. Brading (1975), 154. 
bajo el gobierno de Carlos III, que les permitió un rápido ascenso social. Jorge Chauca observa que, en un inicio, fueron los vínculos sociales y las competencias personales las que les facilitaron el camino, no obstante, la flexibilidad y capacidad de adaptación funcional, fueron claves para ascender a los cuadros de poder ${ }^{2}$.

Un amplio sector de esa comunidad se inclinó por las actividades mercantiles con el capital que emigraron y, para su desarrollo, se apoyaron en las redes de corresponsalías comerciales de sus compatriotas en diversos puntos de Europa y América. Un hecho que desde su llegada a España los situó en conexión con los circuitos del gran comercio internacional, entre ellos los mercados del norte europeo, a través de puertos como Cork, Baltimore y Dublín en Irlanda, Bristol y Londres en Inglaterra, Rotterdam y Ámsterdam en Holanda y Hamburgo en Alemania ${ }^{3}$.

El dinamismo de la comunidad irlandesa en la revolución comercial del siglo XVIII contribuyó a impulsar nuevas formas comerciales, que permitieron el desarrollo del capitalismo comercial en los diferentes lugares en donde se asentaron. En ese sentido, M. ${ }^{a}$ B. Villar observa que sus incursiones en diversidad de mercados y rutas mercantiles les permitieron "poner de manifiesto las potencialidades aun no explotadas de ciertas zonas" y difundir diferentes modelos económicos ${ }^{4}$, influencia que se extendió a impulsar "innovaciones científicas y técnicas que estuvieron en la base del crecimiento de esas ciudades en etapas posteriores"5.

El comercio de vinos fue una ventana de oportunidad para los irlandeses a través de la que accedieron a un rápido enriquecimiento $\mathrm{y}$, con ello, a diversificar sus negocios. Las corresponsalías que tuvieron en el norte de Europa, les permitieron cubrir la demanda que en esos países se tenía de vinos españoles y franceses, destacando Tenerife y Cádiz como los puertos donde prosperaron las compañías de capital irlandés que fortalecieron su actuación como intermediarios del comercio español, un papel que les otorgó ventajas al iniciar el desmantelamiento del monopolio con América.

Óscar Recio, aprecia una evolución y adaptación de la "nación irlandesa" a los diferentes acontecimientos internacionales y a la política que se implementó por los Borbones en la Monarquía hispana, lo que incluyó la revisión a los privilegios ostentados por los comerciantes extranjeros bajo el gobierno

2. J. Chauca García (2016), 65.

3. M. ${ }^{a}$ B. Villar García (1982), 251.

4. M. ${ }^{a}$ B. Villar García (2002), 445.

5. Ibidem, 460 . 
de los Habsburgo. De tal forma, en el periodo de 1759 y 1793, en aras de obtener un mayor control sobre sus súbditos, se establecieron paulatinamente diferentes medidas para dejar atrás la ambigüedad y flexibilidad en la que se manejaron esas comunidades, además de definir "su pertenencia o su exclusión

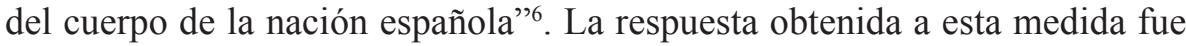
en función de la situación geopolítica de sus naciones frente a España, en el caso irlandés, pasaron de identificarse como pertenecientes a la "nación británica", a hacerlo como "nación irlandesa" y, en 1791, como "ciudadanos españoles", adaptándose con ello a la nueva situación y formalizando su pertenencia a través del arraigo, compromiso y lealtad con el rey español ${ }^{7}$.

En esa evolución al finalizar el siglo XVIII, en un contexto de conflictos bélicos y redefinición de circuitos mercantiles, los irlandeses en la Monarquía hispana actuaron como representantes "de una nación bisagra en la que sus individuos actuaban como agentes y apoderados de otras naciones", gracias a sus nexos entre dos imperios, el español y el británico, con corresponsalías, no solo en las metrópolis, sino en sus colonias americanas, “moviéndose en un único espacio atlántico hispano-británico, común y permeable, hasta convertirse en verdaderas comunidades transimperiales y conectoras de imperios" ${ }^{8}$. Un papel que coincide ampliamente con el caso que se revisa en este trabajo.

Andalucía fue una de las principales regiones receptoras de irlandeses, especialmente los puertos de Cádiz y Málaga, donde alcanzaron gran influencia en la actividad mercantil. María del Carmen Lario, destaca en Cádiz la existencia de una comunidad perteneciente a las "colonias británicas" que, de acuerdo con el censo de 1773, se conformó en su mayoría por irlandeses (87\%), principalmente originarios de Dublín y Waterford, que se integraron exitosamente a la burguesía mercantil gaditana, cobijados por un decreto de Felipe $\mathrm{V}$ que ratificó sus privilegios como súbditos católicos, con lo que pudieron ejercer cualquier actividad ${ }^{9}$. La concesión les permitió comerciar con la América española, ampliar sus redes de negocios y entablar vínculos en espacios intercoloniales del Golfo-Caribe, aprovechando el desmantelamiento paulatino del monopolio mercantil español.

M. ${ }^{a}$ B. Villar destaca que la vinculación de familias irlandesas a las actividades mercantiles y productivas en las ciudades andaluzas les permitió

\author{
6. Ó. ReCIO (2012), 70. \\ 7. Ibidem, 71. \\ 8. Ibidem, 80-81. \\ 9. M. ${ }^{a}$ del C. Lario (2003), 419-421.
}


un rápido enriquecimiento e integrarse a la sociedad exitosamente, lo que se reflejó en la ocupación de cargos públicos y en las nuevas instituciones que se gestaron de orden mercantil ${ }^{10}$. La comunidad irlandesa compartió el entorno en que se desarrolló un amplio sector de comerciantes extranjeros en ambos puertos, con un alto nivel de confort y refinamiento, en residencias elegantes y amplias conformadas por espacios para la vida familiar y los negocios. De manera adicional, para afianzar su rango en la sociedad española, accedieron a un estatus nobiliario con lo que participaron de su sistema de valores, lo que combinaron con la visión cosmopolita que tenían por su trato con el mundo anglosajón y el conocimiento del idioma que utilizaron de forma habitual en sus operaciones ${ }^{11}$.

Málaga siguió un patrón semejante al gaditano y los irlandeses formaron parte del "alto comercio" a través de "casas mixtas" conformadas por extranjeros que se integraron con familias malagueñas que consolidaron una oligarquía comercial ${ }^{12}$. Este puerto, beneficiado por la real instrucción del 16 de octubre de 1765, fue de los primeros en establecer tráfico directo con la América española en el que destacó el comercio de vinos. Además de ello, la comunidad irlandesa realizó inversiones en fábricas de vinos y de aguardientes y participaron en los inicios de la siderurgia en la costa malagueña.

Un elemento extraordinario que avivó el comercio en esa plaza fue la gestión del malagueño José de Gálvez (1776-1787), Secretario de Estado del Despacho Universal de Indias. Sobre quien también fue visitador de la Nueva España, la historiografía lo representa como un reformador progresista y administrador eficiente, sin embargo, también se advierte el nepotismo que ejerció a través de las redes que expandió en la burocracia indiana, conformada por familiares y paisanos malagueños ${ }^{13}$. Algunos autores lo señalan como cabeza de un clan, cuya influencia se convirtió en "casi un mito" que tuvo entre sus integrantes altos funcionarios, incluidos dos virreyes de la Nueva España, su hermano Matías y su sobrino Bernardo de Gálvez ${ }^{14}$.

El comercio malagueño se benefició a través de diferentes medidas de la política de Gálvez: la creación del Consulado Marítimo y Terrestre de

10. M. ${ }^{\mathrm{a}}$ B. Villar García (2002), 459.

11. M. Bolufer Peruga (2009), 188-193.

12. A. Gámez Amián (1994), 116-120.

13. L. Salvucci (1983), 53.

14. M. Hernández (2015), 43-44. 
comercio, el establecimiento de una fábrica de naipes en Macharaviaya y el fomento de la industria vinícola ${ }^{15}$. Para esta última, recomendó abrir nuevos mercados, específicamente el de Irlanda, e impulsar el establecimiento de factorías comerciales en esa nación, así como en Prusia y Hamburgo, lo que sería posible gracias a las gestiones que se realizaban desde Londres.

Para dinamizar el tráfico mercantil, se impulsó la creación de compañías privilegiadas, una con Veracruz (1784) y otra con ruta a Caracas (1787). En el primer caso, se estableció la Compañía de Navieros de Málaga, a la que se le otorgaron los monopolios del abastecimiento de papel para las fábricas de tabaco de Nueva España y naipes a América, a través de la ruta Málaga-La Habana-Veracruz. Esta compañía fue una sociedad anónima de navíos y fletes que ofreció rebaja en sus viajes, la facilidad de contar con un factor en Veracruz y dos buques para el servicio, cuya propiedad se dividió en acciones. Los directores fueron Juan Murphy Elliot, Juan Bautista Maury, Pedro Fisson, Jaime Zetta y Pedro de Campos, mientras que Pedro Porro fue el factor en Veracruz. El 19 de abril de 1785 envió su primer cargamento a Veracruz con vino, vinagre, aguardiente, pasas, aceitunas, hilo, seda de Málaga, encajes, papel blanco de Cataluña y Valencia ${ }^{16}$.

La compañía tuvo dificultades tras la muerte de Gálvez al perder el monopolio de papel en 1790. La situación se agravó con la incorporación de Veracruz y Caracas al sistema de comercio libre que permitió el tráfico directo de otros comerciantes peninsulares a esas plazas, con lo que finalizó la breve exclusividad de la que gozaron los malagueños. Ante las dificultades, las compañías navieras de Málaga y Caracas se fusionaron, resultando de ello la Compañía Marítima de Málaga, de la que Juan Murphy fue otra vez director. A pesar del esfuerzo, Fisson escribió sobre la decadencia de la compañía, pues las expediciones procedentes de Veracruz regresaban "en lastre o con un cortísimo registro de plata" y propuso cargar hoja de tabaco en Nueva Orleans.

Ante la falta de beneficios y la dura competencia, la empresa se disolvió el 19 de junio de 1794, con lo que culminó el breve periodo de auge comercial de Málaga, en parte debido a la falta de protección que había otorgado el ministro de Indias, la competencia de los fletes catalanes que tenían registro abierto para cargar en el puerto y a la falta de interés del capital malagueño ${ }^{17}$. 
Este fue el contexto en el que la familia Murphy desarrolló sus negocios en Málaga, sitio del que partió a Veracruz uno de sus miembros, del que me ocupo en este trabajo, quien reprodujo muchos de los elementos del modelo de inmigración que siguió la nación irlandesa a Nueva España, lugar donde residió durante treinta años, en la que se fue un actor económico y político de primer orden.

\section{TOMÁS MURPHY, CONECTOR DE IMPERIOS}

El patriarca de la familia Murphy en Málaga fue Juan Murphy Elliot, que nació el 27 de abril de 1738 en Waterford, Irlanda y se casó en Gibraltar en 1765 con Bárbara Porro, andaluza con antepasados que se remontan a la nobleza italiana ${ }^{18}$. Ese mismo año el matrimonio se instaló en Málaga, donde nacieron sus nueve hijos: Catalina, Isabel, Ana, María, Juan, Tomás, Mateo, Francisca y Margarita ${ }^{19}$.

\section{Imagen 1. Familia Murphy-Porro.}

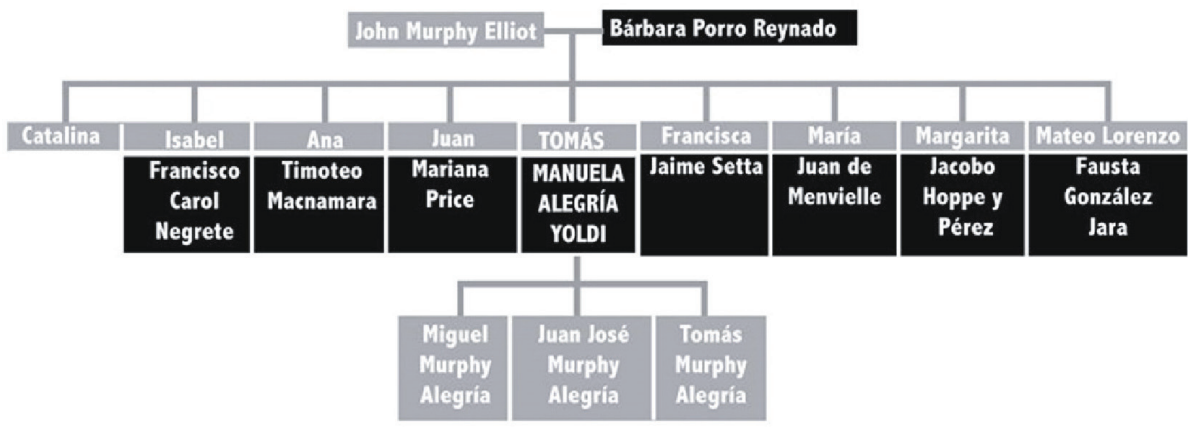

Fuente: G. González Mireles (2018), 63-65.

En la matrícula de comerciantes de Málaga de 1776, Murphy Elliot fue incluido como cosechero, fabricante de aguardiente y naviero, actividades que le permitieron en 1788 confirmar su calidad de hidalgo con una fortuna, en propiedades e inversiones, que sus herederos declararon ascendió a 3 millones 726 mil 386 reales. Tras su muerte, la familia estableció nuevos convenios que

18. V. de Cadenas y Vicent (1956), 131.

19. Archivo Histórico Provincial de Málaga, Protocolos, vol. 3888, fol. 286. Primer testamento de Bárbara Porro, 25 de mayo de 1807. 
garantizaron la continuidad de la casa comercial a los que se vincularon la viuda y sus seis hijas, mientras que Juan Murphy Porro, asumió la dirección de los negocios ${ }^{20}$. Para los estudios sobre el comercio malagueño esta familia no tuvo una permanencia tan sólida como la observada en otros casos, sin embargo, uno de sus miembros se convirtió en uno de los personajes más importantes en los negocios del virreinato novohispano en las últimas décadas.

Tomás Murphy Porro fue el segundo hijo varón, nació el 18 de octubre de 1768 y fue su madrina Teresa Porro ${ }^{21}$. Como correspondía a la formación de un comerciante, en la empresa familiar aprendió "el funcionamiento de las principales técnicas comerciales y financieras, así como adquiriendo las relaciones necesarias para desarrollar con soltura y éxito el oficio" 22 , además de estrechar vínculos con sus miembros, fomentar la confianza y obtener la posibilidad de viajar a alguna plaza de comercio. Aprendizaje que, a Murphy, tempranamente le permitió adoptar una opinión crítica sobre el entorno económico y político, así como del tráfico mercantil entre la Península y la América española, sobre el que criticó las desventajas del comercio malagueño frente a la competencia de otros puertos, pero también observó la falta de una cultura de negocios de los "naturales que esperando nuevas entradas no cuidan de acopiar y así los que se ven precisados a vender para pagar fletes o porque se les cumplan las escrituras de préstamos, sacrifican sus cargas y hacen un barato" 23 .

El 4 de febrero de 1791, Tomás Murphy con 25 años de edad se embarcó en el navío La Prosperidad rumbo a Veracruz, hacia lo que parecía una aventura, sin embargo no lo era, por el contrario fue una estrategia de negocios de una familia que, al amparo de un funcionario poderoso, como José de Gálvez, apreció las oportunidades que se abrieron en el puerto más importante de América y se trasladó para apoyar los negocios familiares al lado de su tío Pedro Porro, que tras la quiebra de la Compañía de Navieros de Málaga, continuó en ese puerto al frente de la firma Porro y Murphy ${ }^{24}$. Esta casa traficó principalmente con textiles, mercería y vino, asociándose con algunos de los comerciantes novohispanos más importantes como lo fue Francisco de Iraeta, con quien negoció azúcar y aguardiente cubano, así como con otros malagueños

20. M. ${ }^{a}$ B. Villar García (1989), 268-269.

21. Archivo Histórico Nacional de España, Consejos, vol. 29351, exp.10.

22. R. Calderón (2004), 121.

23. A. Gámez Amián (1994), 50.

24. Archivo General de Indias, Indiferente, leg. 2113, n. ${ }^{\circ}$ 34. Expediente de solicitud de licencia de embarque de Tomás Murphy, 4 de febrero de 1791. 
establecidos en el virreinato novohispano, Diego Rul y Antonio Pérez Gálvez, yernos del dueño de una de las minas más prosperas en México.

La reputación de la compañía familiar Tomás Murphy la utilizó a favor de sus negocios, en tanto consolidaba su propia trayectoria, así lo demuestra el argumento que utilizó como defensa a una acusación por una factura de vinos alterada, al manifestar que era impensable que "don Juan Murphy, rector de la Compañía de Málaga procediese en este caso con la malicia que se le quiere argüir" 25 . El joven Murphy también aprovechó la ruta y los vínculos de negocios establecidos por la compañía malagueña una vez que su tío Pedro retornó a Cádiz en 1792, asumiendo la rectoría de la empresa e incorporándose al trajín de la vida mercantil del puerto veracruzano en franca expansión tras ser incluido formalmente al sistema de comercio libre en 1789. En esos primeros años, junto con su hermano Mateo Lorenzo, traficó con vino, aceite, textiles, azúcar, granos, harina y algodón con los puertos de Cádiz, La Habana, Barcelona y Campeche, con lo que acrecentó su presencia junto al grupo de comerciantes veracruzanos que en 1795 obtuvieron la autorización para el establecimiento del Consulado de comercio de ese puerto, evidenciando el crecimiento y poder de esa comunidad mercantil. Murphy fue designado en ese primer momento teniente de cónsul segundo y ocupó diferentes cargos en la corporación hasta alcanzar el de prior en 1805.

Siguiendo el modelo de integración que su familia observó en Málaga, Tomás Murphy contrajo matrimonio en 1797 con Manuela Alegría Yoldi, hija de un importante funcionario de la Real Hacienda, Martín Alegría Egues, en ese momento administrador de rentas en Veracruz y de Lorenza Yoldi Valda ${ }^{26}$. Una de las hermanas de Manuela, Josefa Manuela Micaela, se casó en segundas nupcias con José de Azanza, virrey de Nueva España entre 1798 y 1800 . Lo que significó una relación controversial para el malagueño por los señalamientos al favoritismo que recibieron sus negocios durante el periodo de comercio neutral que se autorizó en esos años. La imputación no se alejó de la realidad pues, fue en esa coyuntura que la casa comercial de Tomás Murphy en Veracruz recibió amplias licencias para recibir y cargar diversos productos del giro real (principalmente azogue y papel), plata y otras mercancías en embarcaciones extranjeras (neutras) durante el bloqueo británico al puerto de Cádiz.

25. Archivo General de la Nación México (AGNM), Policía y empedrados, vol. 9, exp. 8, fols. 149-181. Testimonio del expediente formado sobre exceso de aguardiente de los barriles venidos en el bergantín La Sofía, 1792.

26. J. Ortiz de la Tabla (1999), 145. 
Sin embargo, fueron las autorizaciones para "rescatar" cargamentos de naves apresadas por piratas y corsarios en las posesiones británicas del Caribe (principalmente Jamaica), las que fomentaron un flujo incontrolable de mercancías ilegales al virreinato novohispano y causaron el mayor encono hacia el virrey Azanza y Murphy. Ante el descontrol, las licencias a neutrales se limitaron a un núcleo de funcionarios y comerciantes de origen cubano, peninsular, novohispano y estadounidense ${ }^{27}$, en las que se incluyó a Porro y Murphy, distinción que la convirtió en una plataforma internacional al desplegar sus actividades por el Caribe y los puertos del este de Estados Unidos.

En esta primera experiencia Tomás Murphy respondió como un agente eficaz para el gobierno metropolitano y virreinal, al actuar como intermediario con los nuevos socios internacionales, improvisando soluciones ante la confusión por la aplicación de la cambiante legislación mercantil, las discrepancias entre las autoridades y las necesidades financieras de la corona española, correspondiendo a un agente comercial "bisagra". No obstante, la firma dejó de ser funcional para los socios y el 12 de marzo de 1803, Pedro Porro, comisionó a Bernardo de los Cobos para liquidar la sociedad con su sobrino.

Concluida la última guerra anglo-española del siglo XVIII (1796-1802) y con ella la emergencia del comercio neutral, se buscó restablecer el circuito tradicional del comercio novohispano y el malagueño participó activamente en este breve lapso asociado con Miguel de Cotarro y Sopeña en la firma Murphy y Cotarro, especializada en la exportación de azúcar y harina que operó entre 1800 y 1805 en la ruta Cádiz-La Habana-Veracruz. Aunque las licencias a neutrales se habían cancelado, Tomás Murphy aprovechó la influencia alcanzada para expandir sus intereses en los circuitos de comercio internos novohispanos a otras regiones de la Monarquía con productos de exportación demandados en el mercado mundial: tintes (grana cochinilla, palo de tinte y añil), cacao, cueros, etcétera, con lo que consolidó su estatus económico y político en el virreinato.

No obstante, el negocio que lo posicionó como uno de los comerciantes más influyentes en la Nueva España vino con la guerra al actuar como agente de la casa Gordon y Murphy, sociedad mercantil que inició como distribuidora

27. Los socios internacionales implicados fueron: Tomás Buchanan de Nueva York, la Casa de Jaime Barry, de Baltimore, y Tunno y Cox de Charleston. Entre los cubanos estaban el conde de Mopox y Francisco de Arango y Parreño, Carlos Martínez de Irujo y José María de Iznardi. 
de vinos en 1802, fundada por su hermano Juan Murphy y William DuffGordon $^{28}$. Las complicaciones geopolíticas y bélicas que demandaron una cantidad de recursos sin precedentes, fueron la llave que abrió la oportunidad para esa firma hispano-inglesa. Por un lado, el Tratado de Subsidios de 1803, obligó a la corona a pagar un subsidio anual a la tesorería francesa, y por otro, la guerra contra Inglaterra a la que España se incorporó en diciembre de 1804 , la llevaron a tomar medidas extractivas sin precedentes y extendió la real orden de Consolidación de Vales Reales a sus súbditos americanos para respaldar los préstamos contratados, hecho que para algunos autores significó una medida de la que partió la fractura final con sus colonias americanas ${ }^{29}$.

El traslado de la plata novohispana fue el principal problema a solucionar, en un primer momento se encargó al financiero francés Gabriel Ouvrard, sin embargo, el complejo esquema de operaciones y socios internacionales resultaron en detrimento de los intereses reales, lo que involucró a Gordon y Murphy en el negocio. Esta sociedad firmó en 1806 contratas secretas con la Real Caja de Consolidación y la Tesorería inglesa para, de forma encubierta, mover caudales, correspondencia, productos del real giro y manufacturas británicas en medio de la propia guerra que libraron. El monto de plata que se autorizó extraer fue de 10 millones de pesos que pasarían libremente por el Caribe con pasavantes expedidos en Londres o por el gobernador de Jamaica.

Tomás Murphy fue el agente de la firma en la Nueva España, encargado de resolver cualquier traba administrativa ante los funcionarios, vender la mercancía, extraer el metálico y productos de exportación, en suma, gestionar la operación de la infraestructura de negocios internacional entre dos imperios en conflicto. Cuando la guerra incomunicó a la metrópoli de sus colonias, las expediciones de la firma prácticamente actuaron totalmente libres, sin más control que aquel que pudieran tener las autoridades del puerto de embarque y desembarque, lo que permitió a Murphy participar en una descontrolada ruta de tráfico mercantil entre Veracruz, Cuba y Jamaica a través de las embarcaciones para el servicio del correo y la modalidad de "rescates" ${ }^{30}$. Operaciones que causaron molestia, reclamos y suspensión de sus actividades como agente de la firma, seguidas de una tensa negociación por "aclarar" las cuentas de la empresa, que fueron resultas con la presencia de Murphy en Madrid en $1822^{31}$.

28. G. JiMÉNEZ (1991), 225-230.

29. C. Marichal Salinas (2015), 181-185.

30. G. GonzÁlez Mireles (2018), 49.

31. Ibidem, 128-130.

(C) Baetica. Estudios Historia Moderna y Contemporánea, 40, 2020, 173-193. Facultad de Filosofia y Letras, Universidad de Málaga. Departamento de Historia Moderna y Contemporánea 
Nuevamente, la coyuntura internacional marcó el rumbo de la trayectoria del comerciante, pues al convertirse España e Inglaterra en aliadas contra el invasor francés, fue nombrado agente de la Tesorería inglesa para extraer de las arcas novohispanas 10 millones de pesos que la Junta Suprema de España autorizó en 1810. Su cercanía y participación directa en el circuito de mineros mexicanos le permitió cumplir con la tarea recolectando el $85 \%$ de la suma ${ }^{32}$.

Los negocios que Tomás Murphy desarrolló en el plano internacional, a través de las diferentes experiencias señaladas, lo convirtieron en un personaje trascendental en la vida política y económica en México y, al iniciar su gesta insurgente, rechazó la violencia del movimiento armado y mantuvo su apoyo al régimen liberal español. No obstante, conforme la guerra se recrudeció y Fernando VII regresó al trono español, negoció con los insurgentes mexicanos y al mismo tiempo con el bando realista, en un complejo sistema de equilibrio de intereses políticos y de negocios. El mismo que mantuvo hasta el final del movimiento independentista, al grado de conocer el plan de consumación de Agustín de Iturbide poco antes de salir del casi extinguido virreinato en febrero de 1821 a España ${ }^{33}$.

A pesar de conocer la consumación de la independencia mexicana, Tomás Murphy participó como diputado a Cortes en el último periodo al que asistió una comitiva novohispana, manifestando en sus diversas intervenciones la justa independencia de los territorios americanos de la metrópoli, no obstante, esta debería de ser conciliada. Coincidió con otros irlandeses que vivieron en América, al apreciar que la riqueza sería posible en un "imperio cohesionado e interdependiente que no tenía nada que envidiar a otras potencias, si acaso imitar en beneficio propio" 34 . Una postura que expuso a través de su participación en comisiones y discusiones sobre materia comercial, fundando su argumento en casi treinta años de trayectoria mercantil en los que observó los beneficios del comercio libre para la Monarquía. Sobre este, opinó que debía ser regulado por un modelo igualitario entre los españoles de ambos hemisferios, conciliando los intereses de la agricultura y la industria entre sus provincias, así como protegiendo las industrias regionales con altos aranceles a productos extranjeros, además de gobernarse bajo una administración sencilla, clara y uniforme, en un

32. AGNM, Indiferente Virreinal (IV), caja 297, exp. 11. Certificación de Juan González Ferino, administrador general de la Real Aduana de Veracruz.

33. L. Alamán (1849), 78.

34. J. Chauca García (2016), 63. 
modelo que favoreciera a los integrantes de la Monarquía hispana en su conjunto, reafirmando los lazos y la génesis que compartían peninsulares y americanos para fortalecerse y obtener ganancias equilibradas ${ }^{35}$.

La claridad de sus argumentos y la visión global que expuso sobre los negocios internacionales, además de provenir de su experiencia, también reflejaron el singular papel que la nación irlandesa jugó para el régimen borbón y que encuentra en Tomás Murphy un ejemplo ilustrativo del modelo planteado para la Península. Así, en un primer momento se estableció en Veracruz bajo la protección de una compañía privilegiada que facilitó su inserción en la sociedad de ese puerto, la que se reforzó al compartir valores católicos, su temprana participación en asuntos locales y una alianza matrimonial. Por otro lado, el desmantelamiento del monopolio mercantil español y las guerras del periodo lo llevaron a servir como interlocutor del monarca español con Inglaterra y Estados Unidos, encargo que se extendió también a representar los intereses de los grupos novohispanos, que preparó el camino para un diálogo propio y con ello el ideal autonomista. Sus participaciones como agente y apoderado de la casa Gordon y Murphy y de la Tesorería británica, se adhieren bien a la definición de Recio sobre los miembros de la comunidad irlandesa, como conectores de imperios. Mientras que los vínculos que entabló con las élites indianas lo sitúan en la mediación intercultural entre europeos y americanos señalada por $\mathrm{Chauca}^{36}$.

Otro rasgo distintivo de este comerciante, que coincide con las contribuciones de la comunidad irlandesa identificadas por M. ${ }^{a}$ B. Villar, fue su papel en el fomento de prácticas "modernas" en los negocios que marcaron la pauta a otros comerciantes mexicanos, entre ellas, el uso habitual de instrumentos financieros para operar en los centros de negocio del mundo, sobre los que señaló:

Este es un arbitrio sancionado por el común consentimiento de los hombres y tan practicado en las plazas de Europa como ignorado en las de América y poco conocido en sus tribunales de comercio por un efecto precio de la corta circulación de nuestro giro y relaciones mercantiles ceñidas a recibir efectos y retornar moneda y frutos ${ }^{37}$.

35. G. González Mireles (2018), 178-179.

36. J. Chauca García (2016), 11.

37. AGNM, IV, caja 3281, exp.14. Dictamen del tribunal y contaduría mayor de la ciudad de México. 
Además de fomentar el uso de nuevas formas comerciales, Murphy incidió en el desarrollo de prácticas médicas modernas y en innovaciones técnicas del proceso minero. Sobre lo primero, en su visita a la Nueva España, el barón de Humboldt dejó testimonio de que fue él quien introdujo la vacuna contra la viruela y apoyó la expedición de Francisco Xavier de Balmis en 1804. Su interés por la medicina se reflejó también a favor de otro médico que visitó el virreinato, el italiano Esteban Curti, condenado al exilio por el Tribunal del Santo Oficio por sus opiniones y prácticas científicas. Al parecer el malagueño deseaba que atendiera el parto de su esposa de un hijo que, finalmente falleciós ${ }^{38}$. En otro episodio relacionado a la práctica médica, la Inquisición abrió un expediente en su contra por unos libros que llegaron en una de sus embarcaciones ${ }^{39}$.

Respecto a la minería, Tomás Murphy tomó parte en todos los aspectos de la cadena de valor del producto, además de comercializarla, fue socio de una compañía conductora del metal y se involucró en su producción al adquirir acciones en algunos de los centros mineros más prósperos de México. Uno de ellos fue Real del Monte, en donde poseyó acciones en la mina del Morán, que posteriormente fue explotada por la Compañía inglesa de Real del Monte. En el proceso productivo minero, Murphy también buscó innovar con la propuesta de introducir y comercializar la máquina de vapor para el desagüe, petición que le fue negada y que finalmente logró obtener su hermano Juan Murphy. La primera de ellas llegó en marzo de 1822 destinada al complejo minero de Real de Catorce ${ }^{40}$.

No obstante, el papel relevante que Tomás Murphy tuvo en la sociedad novohispana, su salida era inminente para alcanzar a su familia que desde 1813 estaba en Europa a resguardo de la lucha insurgente, además de finalmente arreglar la controversia que tenía con la casa Gordon y Murphy, y con su hermano Juan, socio de la misma, lo que finalmente ocurrió el 3 de febrero de 1821 en la fragata La Pronta ${ }^{41}$.

38. AGNM, Inquisición (I), vol. 1255, fols. 263-265. Denuncia del presbítero Lucas José Fichere y Souza contra Dionisio de Alcalá Galiano, comandante del navío La Minerva y contra Tomás Murfi.

39. Las obras médicas detenidas en la Aduana de México fueron: Anatomía de Bichat, Anatomía de Portal, Anatomía de Boyer, Chimica de Cadet, Farmacopea clínica, Farmacopea de Beaume, Enfermedades orgánicas del corazón, Observaciones sobre la fiebre amarilla, Nueva Higiene militar, Tratado de las enfermedades sifilíticas, Obras de Tisot, Filosofía médica y Filosofía botánica. AGNM, I, vol. 1440, fol. 260.

40. G. GonZÁlez Mireles (2018), pp. 131-133.

41. AGNM, IV, caja 3121, exp. 2. 
En el complejo sistema de equilibrios que jugó dentro del virreinato, Tomás Murphy asumió una postura de apoyo a la autonomía mexicana que le ganó respeto y estima de varias figuras protagónicas de la nueva nación, pero también fue apreciado por la solución inmediata que brindó a una problemática común en las nacientes naciones americanas por la falta de hombres cosmopolitas con una visión internacional de los negocios y la geopolítica para representar sus intereses diplomáticos y financieros ${ }^{42}$. Esa carencia, para Murphy fue ventaja frente a la creciente necesidad de comunicación con actores internacionales implicados en el tráfico mercantil (especialmente del mundo anglosajón), al ofrecer una solución eficiente ante la ausencia de hombres con estas ventajas culturales en el virreinato novohispano.

Es probable que esta situación aminorara para el comerciante la "permanente tensión cuando el apellido extranjero era objeto de un permanente ataque político y el propio individuo afectado era plenamente consciente" que Recio plantea para la comunidad irlandesa ${ }^{43}$. Pues a pesar de los señalamientos que recibió como representante de los intereses británicos e identificarlo habitualmente como ciudadano inglés, esto no le representó grandes dificultades para integrarse exitosamente a la sociedad novohispana. El cuestionamiento a su identidad provino tras la independencia mexicana, actuando como representante diplomático del gobierno mexicano, primero en Londres y después en París, al exigirle su retiro para dar cumplimiento a la ley federal de empleos para la destitución de españoles de todo cargo público y del decreto de expulsión de México en 1827.

El comerciante malagueño acató la orden, no obstante, la estima por su persona y capacidad para resolver problemas diplomáticos y financieros de la naciente república mexicana, favorecieron a su hijo Tomás Murphy Alegría, quien fue nombrado secretario de la Legación mexicana en París, a partir de lo que desarrolló una amplia trayectoria en el servicio exterior mexicano.

A pesar de que la lógica de los negocios explica en gran medida las filias y lealtades en los diferentes momentos de la trayectoria de Tomás Murphy, al final de su vida solicitó al presidente mexicano Vicente Guerrero eximirlo del decreto de expulsión de españoles para regresar a la república mexicana "país al que eligió por patria desde 1791", pues

42. A. Lempérière, (2004), 126.

43. Ó. Recio (2010), 110. 
"gozando yo por mi origen de los derechos de súbdito británico, podría muy bien trasladarme a México sin necesidad de especial permiso, pero prefiero hacerlo como mexicano" ${ }^{44}$. La petición pone de manifiesto que no estuvo exento de entender y sentir el conflicto de indefinición de los novohispanos que se convirtieron en mexicanos y del que él mismo, probablemente se sintió parte. La respuesta del gobierno mexicano no llegó y pocos meses después su hijo avisó de su muerte acaecida en Toulouse el 13 de febrero de 1830 .

Los testimonios de algunos contemporáneos de Murphy lo valoran positivamente al señalar una genuina simpatía por la causa de los mexicanos, como Lucas Alamán que al escribir sobre el restringido grupo de hombres que conocieron tempranamente el plan para consumar la independencia, sobre él señaló: "no se tuvo desconfianza alguna, pues eran conocidas sus opiniones favorables a la independencia y nadie dudaba de su pundonor" 45 . Lorenzo de Zavala dejó testimonio de que el comerciante "había manifestado constantemente adhesión a su patria adoptiva" a través de acciones como la circulación de impresos y su participación en diferentes conspiraciones autonomistas. Por su parte, José María Luis Mora lo distingue como "español y de origen irlandés" y observó un afecto sincero a la independencia pero obligado "a disimular sus sentimientos entre hombres que no se los hubieran perdonado" 46 .

Respecto a opiniones desfavorables, Juan López de Cancelada, férreo opositor del libre cambio, lo denunció como contrabandista, de valerse "de mil ardides" y de "fomentar en otros novohispanos estas mismas prácticas" ${ }^{4}$. Acusaciones que años después se resumieron a señalarlo como especulador frente a los intereses británicos.

En suma, los actores políticos mexicanos reconocieron la contribución del malagueño en la construcción del nuevo país, que se asentó en la esquela que publicó la Gaceta del gobierno mexicano, donde distinguió "sus talentos y sus servicios a la república" en el exterior. Además, "porqué consideró y sirvió a México como a su propia patria. Lo era en efecto por adopción, y por todas las afecciones que unen la suerte del hombre a la de un país"48.

44. J. Flores (1951), 29.

45. L. Alamán (1849), 73.

46. J. L. M. ${ }^{a}$ Mora (1965), 230.

47. J. López Cancelada (1989), 69.

48. Gaceta del Gobierno de México, 5/5/1830. 


\section{CONCLUSIÓN}

La trayectoria de Tomás Murphy en la Nueva España cobra trascendencia al comprenderla dentro del proceso de modernización de la Monarquía hispana, la guerra de intereses entre imperios y el reacomodo políticoeconómico de las élites indianas. La vertiginosidad y complejidad con la que se suscitaron las transformaciones de la época, lo colocaron como interlocutor de los protagonistas de coyunturas decisivas en el nacimiento de la nación mexicana, de la que se sintió parte hasta el final de su vida. La dualidad de su origen, irlandés y malagueño, le proporcionó ventajas culturales y vínculos sociales para convertirse en un agente eficiente en un mundo en transición, que requirió una visión cosmopolita, conocimiento y presencia en el ámbito internacional de los negocios, especialmente con el mundo anglosajón.

Al margen de los beneficios personales que obtuvo por su intermediación entre los actores políticos y económicos, es innegable su aportación en la resolución de eventos trascendentales que culminaron con la génesis del nuevo país y que invita a reflexionar en la contribución de la comunidad irlandesa a las historias nacionales de las naciones americanas, como otra pieza del gran mosaico que fue la Monarquía hispana, y que explica, una realidad compleja e interconectada.

\section{BIBLIOGRAFÍA}

Alamán, Lucas (1849), Historia de México desde los primeros movimientos que prepararon su independencia en el año de 1808 hasta la época presente, t. V, Imprenta de J. M. Lara, México.

Bolufer Peruga, Mónica (2009), "Irlandeses en España: los Trenor y otros más", en A. Pons y J. Serna (eds.), Trenor. La exposición de una gran familia burguesa, Universitat, Valencia, pp. 165-198.

Brading, David (1975), Mineros y comerciantes en el México en el México borbónico (1763-1810), Fondo de Cultura Económica, México.

Cadenas y Vicent, Vicente de (1956), Caballeros de la orden de Alcántara que efectuaron sus pruebas de ingreso durante el siglo XIX, Ediciones Hidalguía, Madrid.

CALDERÓn, Reyes (2004), Empresarios españoles en el proceso de independencia norteamericana: La Casa Gardoqui e hijos de Bilbao, Unión Editorial, Madrid.

Chauca García, Jorge (2016), José de Gálvez, mentor del irlandés Ambrosio Higgins en España y América, Universidad, Málaga.

Flores, Jorge (1951), Lorenzo de Zavala y su misión diplomática en Francia (1834-1835), Secretaría de Relaciones Exteriores, México. 
Gámez Amián, Aurora (1994), Málaga y el comercio con América (1765-1820), Miramar, Málaga.

González Mireles, Gabriela (2018), Historia de un comerciante en una época de transición: 1797-1821. Tomás Murphy, Ed. Unas Letras, Mérida.

HernÁnDEZ, Manuel (2015), "El círculo de los Gálvez: formación y ocaso de una élite de poder indiano", Catharum. Revista de Ciencias Sociales y Humanidades, 14, pp. 49-80.

JimÉnez, Guadalupe (1991), La Gran Bretaña y la Independencia de México 1808 1821, Fondo de Cultura Económica, México.

LACOMBA, Juan Antonio (1973), "Málaga a fines del siglo XVIII: una ciudad próspera," Jábega, 2, pp. 61-64.

LARio, María del Carmen (2003), "Irlandeses y británicos en Cádiz en el siglo XVIII", en M. a B. Villar García y P. Pezzi Cristóbal (eds.), Los extranjeros en la España moderna, t. I, Ministerio de Educación y Ciencia, Junta de Andalucía, Patronato de la Costa del Sol, Asociación Hispano-Alemana de Málaga y la Costa del Sol, Consulado General de Alemania, Unicaja, Universidad, Ayuntamiento y Diputación Provincial de Málaga, Málaga, pp. 417-425.

LEMPÉRIÈRE, Annick (2004), "El paradigma colonial en la historiografía latinoamericanista", Istor. Revista de Historia Internacional, 5, 19, pp. 107-128.

López Cancelada, Juan (1989), Defensa de la Nueva España miscelánea, M. A. Porrúa, México.

Marichal Salinas, Carlos (215), "Plata mexicana para Napoleón I. La consolidación de vales reales y el comercio neutral en Veracruz, 1805-1808", en P. MARTíNEZ López-CANo (coord.), De la historia económica a la historia social y cultural. Homenaje a Gisela von Wobeser, Universidad Nacional Autónoma de México, Instituto de Investigaciones Históricas, México, pp. 181-212.

Mora, José María Luis (1965), México y sus revoluciones, 3 tomos, Editorial Porrúa, México.

ORTIZ DE LA TABLA, Javier (1999), “Comercio neutral y redes familiares a fines de la época colonial”, en E. Vila y A. Kuethe (eds.), Relaciones de poder y comercio colonial. Nuevas perspectivas, Escuela de Estudios HispanoAmericanos, Sevilla, pp. 143-172.

Recio, Óscar (2010), "El lastre del apellido irlandés en la España del siglo XVIII”, en G. Salinero e I. Testón (comps.), Un juego de engaños. Movilidad, nombres y apellidos en los siglos XV a XVIII, Casa de Velázquez, Madrid.

- (2012), "Las reformas carolinas y los comerciantes extranjeros en España: actitudes y respuestas de las «naciones» a la ofensiva regalista, 1759-1793", Hispania. Revista Española de Historia, LXXII, 240, pp. 67-94.

SAlvuCCI, Linda (1983), “Costumbres viejas, 'hombres nuevos’: José de Gálvez y la burocracia fiscal novohispana (1754-1800)", Historia Mexicana, 33, 2, pp. 224-264. 
Santos, M. ${ }^{a}$ Soledad (1994), "La gestión del consulado del Mar de Málaga: 17851787”, Espacio, Tiempo y Forma, IV, 7, pp. 365-376.

Villar García, M. ${ }^{a}$ Begoña y García Montoro, C. (1989), "El capital mercantil en las crisis de principios del siglo XIX. Tres ejemplos malagueños", Baetica. Estudios de Arte, Geografia e Historia, 12, pp. 261-278.

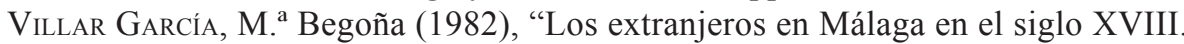
Resumen de una investigación”, Baetica. Estudios de Arte, Geografía e Historia, 5, pp. 205-214.

- (2002), "La contribución irlandesa al progreso de Europa en el siglo XVIII: militares, políticos y comerciantes", Baetica. Estudios de Arte, Geografía e Historia, 24, pp. 445-460. 